\title{
Foucault and deaf education in Finland
}

\author{
Lauri Siisiäinen \\ Department of Social Sciences and Philosophy \\ University of Jyväskylä \\ Email: lauri.m.siisiainen@jyu.fi
}

\begin{abstract}
The influence of Michel Foucault's thinking in critical disability studies, and to social studies of deafness, can hardly be doubted. Foucault has offered valuable tools for the critical rethinking of deaf education and pedagogy with respect to normalization and disciplinary power, which are integrally related to the historical construction of deafness as deficiency and pathology by modern, medical, and psychological knowledge. This article explores the applicability and critical potential of the Foucauldian concepts of disciplinary power, surveillance, and normalization within the specific context of the history of deaf education in Finland. The article focuses on the modernization of the education of deaf children that began during the latter half of the nineteenth century in Finland, with the influence of oralism - a pedagogical discourse and deaf-education methods of German origin. Deafness was characterized as a pathology or abnormality of the most severe kind. When taken at the general level, Foucault's well-known concepts are easily applicable to the analysis of deaf education, also in the Finnish context. However, it is argued that things become much more complex if we first examine more closely the roles played by the eye and the ear, by optic and aural experience, in these Foucauldian notions, and if we then relate this enquiry to our analysis of oralist pedagogy and deaf education.
\end{abstract}

Keywords: deaf education, deafness, oralist pedagogy, oralism, normalization, disciplinary power, Finland

\section{Introduction}

The significant influence of Michel Foucault's thinking in critical disability studies can hardly be doubted (Allan et al., 1998; Allan, 2007; Tremain, 2005). This is also the case when it comes to social studies of deafness. Foucault's work especially the seminal concepts he coined in the 1970s - has offered valuable tools for the critical, problematizing, and de-naturalizing rethinking of deaf education and pedagogy with respect to normalization and disciplinary power, which are integrally related to the historical construction of deafness as deficiency and pathology by modern, medical, and psychological knowledge (Bauman, 2004; Branson and Miller, 2002; Lane, 2002). The article contributes to this topical discussion and further probes the applicability and critical potential of the Foucauldian concepts of disciplinary power, surveillance, and 
normalization, within the specific context provided by the history of deaf education in Finland. ${ }^{1}$

First, I focus on the modernization of the education of deaf children that began during the latter half of the nineteenth century. In this reform, the import of oralism, a pedagogical discourse and deaf-education methods of German origin, played a prominent role. I shall show that oralist pedagogy is underpinned by a binary opposition of the ear and the eye, or sense of hearing and sight. In this setting, the sense of hearing and aural experience are determined as the origin and necessary condition of 'normal subjectivity', the ability to think rationally and to use abstract concepts. According to the oralist doctrine, it is only through the speaking voice and aural experience that a thinking subject can be born, one who has a permanent and coherent identity.

It follows that deafness - the lack of hearing and ability to speak - is characterized as a deficiency and pathology or abnormality of the most severe kind. Allegedly, it hampers the entire development of human being and the separation of the human from animal life. As purely visual and silent, the sign or gesture language used by the deaf is judged as inherently non-conceptual. The only way to make the deaf 'truly human', the central objective of deaf education, is to give them voice, speech, and aural experience. We shall discover how these oralist notions were elaborated, put into practice, and institutionalized in Finland over time. Despite opposition and despite the weakening of the German influence, they have remained influential even up until today in modified forms.

At a general level, Foucault's well-known concepts of modern disciplinary, surveying, and normalizing power are easily applicable to the analysis of deaf education, including in the Finnish context. However, the article contends that things become much more complex if we first examine more closely the roles played by the eye and the ear, by optic and aural experience, in these Foucauldian notions, and if we then relate this enquiry to our analysis of oralist pedagogy and deaf education. This is something which, to my knowledge, has hitherto been missing in critical deafness studies that draw upon Foucault.

The article seeks to substantiate that in Foucault's analyses of disciplinary, surveying and normalizing power - in fact, these three belong integrally together - there are no parallels to what has taken place with the oralist pedagogy and education of deaf children in Finland, as well as elsewhere: the production of normality through voice-ear-aural experience, and the pathologization of visuality and silence. More serious, from this angle, is Foucault's strong insistence on the purely optic-visual modus operandi of modern discipline and normalization, together with the characterization of the ear and aural experience as the adversary of normalization and discipline. This does not leave much room for the recognition and critical analyses of such cases as the history of oralism and deaf education. If critical thinking and theory are to keep a critical impetus and even strengthen and expand it and to avoid the exclusion of particular phenomena as being beyond critique, they need to engage in this kind of selfcritical reflection on the taken-for-granted presumptions lurking in their own language.

\footnotetext{
1 Primary sources or even studies on the early history of Finnish deaf education are somewhat difficult to find. Below, I mainly draw upon the study by Salmi \& Laakso (2005). Although published by Finnish Society of the Deaf, which is not an academic publisher, it is credible in its use of historical material. Primary sources or even studies on the early history of Finnish deaf education are somewhat difficult to find. Below, I mainly draw upon the study by Salmi \& Laakso (2005). Although published by Finnish Society of the Deaf, which is not an academic publisher, it is credible in its use of historical material.
} 


\section{Oralism in deaf education (I): Johann Conrad Amman}

The German school of deaf education, developed in the eighteenth century, had a great impact on the Nordic countries, including Finland. Therefore, we need to begin with a concise discussion of this school: the pedagogical discourse of oralism (a set of central notions and arguments) as well as the related oralistvocal-aural methods of teaching deaf children. Generally, it is thought that the birth of German school dates back to the late seventeenth century to Johann Conrad Amman (1669-1724), who was a Swiss medical doctor. Amman's views on deaf education are based on the belief on the unique, privileged status of voice and vocal speech as media of expression and communication. Voice is the most immediate, the most faithful, the most truthful, and the most certain sign expressing and conveying the interior life of the mind, both emotions and ideas or conceptions:

There is still a very different reason, why men should desire to open the secrets of their hearts and the conception of their minds to others in speech rather than by pictures, gestures, or characters, and other things of this kind (...) for nothing emanates from us which bears a more vivid character of life than our Voice; neither have I gone beyond the truth in affirming that the breath of life resides in the voice, transmitting its light through it; for the voice is the interpreter of our hearts and signifies its affections and desires. (Amman, 1873, pp. 7-8, emphasis added)

As we find out, any visual medium and genre of signs, pictures or gestures is condemned as being essentially defective in comparison with voice. They are mediated, partial, incomplete, and deceptive in their signifying power (Amman, 1873 , pp. 7-8). In this respect, Amman's argument is reminiscent of what Derrida (1967) has called phono/logocentrism (see Bauman, 2004; 2008). Voice is also the most natural and primary vehicle for the deaf to express their feelings, affects, and sensations: 'Deaf Men Laugh, Cry out, Hollow, Weep, Sigh, and Waile, and express the chief Motions of the Mind, by the Voice' (Amman, 1694, ch. I).

However, what they remain incapable of, most essentially, is articulate vocal speech and understanding of speech. Through their non-speaking voice, they may give a subjective expression to their own affects and sensations. Still, without speech, they are unable to form, convey, understand, and learn concepts and ideas. What results from this is the necessary predicament in the development of the higher, conceptual mental faculties, that is, of intellect together with moral sense of duty. The 'enlightenment' of these faculties can only occur through the circulation of speech. Consequently, the deaf remain attached to the life of sensations and affects (Amman, 1873, pp. 2-3).

Most importantly, Amman asserts, the silent language of gestures used by the deaf can never compensate for the deprivation of speech in education, through which the higher, properly 'human' spiritual capacities could be realized. Hence, the deaf are stuck somewhere between human being and animal:

How dull are they in general! How little do they differ from animals (...) And even if their parents are most attentive to them, how inadequate and defective is the language of gestures and signs which they must use! (...) How little do they comprehend, even superficially, those things which concern the health of the body, the improvement of the mind, or their moral duties! Who does not pity their wretched condition? Who will refuse to relieve it by all the contrivances which can be devised? (Amman, 1873, pp. 2-3, emphasis added) 
In this manner, giving deaf people the ability to speak and to understand the speech of others and replacing the 'primitive' and defective sign language with speech becomes the primary objective of deaf education. Otherwise, all attempts to educate and teach deaf children - to develop their intellectual and moral powers, to emancipate them from their 'dullness' - are doomed to failure. Only by making them speak and understand speech, instead of using silent gestures, can the deaf become detached from their animal existence and be elevated to the rank of true humanity.

In Amman, the strong influence of Christian ideas is explicit when he attempts to legitimate the urgency of the task of making the deaf speak:

Voice is a living emanation of that spirit which God breathed into man when he created him a living soul (Amman, 1873, p. 10) (...) I will state some preliminary axioms of indisputable truth, by which it will be shown from the nature of God, that creatures formed in his image ought, of necessity, to be able to speak and in this respect resemble their Creator (...). (Amman, 1873, pp. 12-13, emphasis added)

God is endowed with the capacity to speak, that is, to convey ideas or concepts in an articulate voice that preserves their meaning without any distortion. Thus, the human being, the 'image of God', must have this capacity also (albeit less perfect than God's, of course), and the lack of it equals nothing less than falling short of humanity. Although not totally lacking, the capacity to speak remains dormant in the deaf-mutes. Relatedly, what also remains dormant is the human power to govern both oneself as well as others, to govern the whole of nature, again in the model of God. It is only with speech that the active human subject, the ruler of the earth, is created:

At last, the eternal Word (...) creates Adam, that is Man, in his own image, and commanded him to subject the land and sea and all the host of them to himself; but to the end that he might properly exercise this empire over them, it was necessary that Adam himself should have effectually the power of commanding, the force of which consists in an emanating word. (Amman, 1873, pp. 14-15, emphasis added)

This religious justification is hardly surprising or original. Rather, Amman is reiterating the doctrinal belief - dominant in the Christian church already in the Middle Ages - that the deaf are separated from the Word of God, from the Christian community, and from education. It had become a commonplace to authorize the exclusion of the deaf by reference to Paul's Letter to the Romans: 'faith cometh by hearing, and hearing by the word of God' $(10: 17)$. The established opinion of the church was that the use of gestures, such as silent sign language, could never match hearing and vocal speech as the medium of religion (Knowlson, 1965).

Yet Amman thought that the deaf could be released from their state of incapacity. They could be 'humanized' with apt methods of education. Through these methods, it would be possible to activate the capacities to produce and understand speech that were latent in the deaf:

After close investigation, I found that most of the mutes have their organs of speech perfect, and that they are speechless because they are deaf (Amman, 1873, p. 3, emphasis added) (...) For human speech, as will appear to every one who considers it with a little attention, is a certain 
combination of many different kinds of sound, the variety of which arises, in my opinion, from the various motions of certain organs, which if they were sufficiently visible, I should think, would suffice for the deaf to discern them with their eyes, just as others receive sounds through their ears; and thus, in time, they may learn to speak. (Amman, 1873, pp. 3-4, emphasis added)

\section{Oralism in deaf education (II): Samuel Heinicke}

Amman's ideas, in turn, were a major influence on Samuel Heinicke (17271790), a Prussian teacher. It was largely through Heinicke that the oralist discourse and methods of teaching were institutionalized into what came to be known as the German school of deaf education (Lane, 1984, pp. 100-103). Moreover, it was to a great extent via Heinicke that oralist pedagogy became established in the Nordic countries, when deaf education was reformed there in the course of the nineteenth and twentieth centuries. Hence, Heinicke's thought needs to be discussed in some detail.

The backbone of Heinicke's pedagogical thinking is provided by his empiricist philosophical position, inspired to some extent by John Locke. In summary, Heinicke jettisons the notion of ideas and principles that would be innate in the mind. The mind is initially empty, while all knowledge originates in sensual perception. As Amman did before, Heinicke submits that thinking has its origin and its necessary prerequisite in spoken language. Thinking is a process that takes place in the mind only by means of the sounds uttered in talking, that is, through words as phonetic and auditory units. Thinking cannot occur independently of and detached from this perceptual, aural-vocal basis. Heinicke infers that those who cannot speak or hear, or both - in other words, deaf people - cannot think either, or at least, they cannot think abstractly or conceptually. At best, without speaking voice and aural experience of words, the deaf can think in merely concrete terms. The higher stages of abstract and conceptual thinking can only be reached through the regular use of vocal speech and the aural experience of words (Arnold, 1984; Markowicz, 1972).

In Heinicke's thinking, as it was with Amman, the privilege of voice and aural experience has its reverse in the inferiority of sight and visual experience: 'It is a mistake to believe that the sense of sight, through written speech, can replace the sense of hearing for deaf mutes. Abstract concepts cannot be developed through the aid of writing' (cited from Markowicz, 1972, p. 21, emphasis added). Writing and reading, just like manual communication with gestures, cannot by themselves evoke the sounds of words in the mind. Hence, they cannot offer the solid medium needed for the communication and understanding of abstract concepts:

(W)e must not believe that because words permit themselves to be represented on paper that they therefore can be similarly presented inside ourselves. No, this in no way follows. Written or printed words are like heaps of flies' feet or spiders' legs; they are not forms or figures that can be presented as fixed or abstracted in our imagination; and we are hardly able to represent individual letters to ourselves subjectively with any continuity. (Cited from Markowicz, 1972, p. 21, emphasis added)

As we can observe in the quotation, Heinicke sets forth his variation of the binary setting of the ear and the eye. Also in Heinicke's version, the voice, the ear, sense of hearing, and aural experience are determined as the necessary origin

NJSR - Nordic Journal of Social Research 
and condition of normal adult subjectivity, and, even more fundamentally, of the formation of human beings as separate from animals. With Heinicke, this setting becomes perhaps still more explicit and meticulous than with Amman. Heinicke argues that only voice and aural experience can give the firm medium, through which can develop the higher faculties and activities of the mind, ones that operate with abstract concepts, ideas or notions. Only voice and aural experience can offer the medium that supports and safeguards the permanence, unity, coherence, and clarity of concepts and abstract thinking, and of the thinking subject itself, over and against the flux of sensations and affects. Only voice and aural experience enable our memory to grasp and keep words and concepts so that they remain the same in their meaning.

In opposition to this, Heinicke proposes, our eyes, visual experience and visual signs are bound to the concrete, which is to say, to the flow of shifting and vanishing impressions and affects. In a rather mysterious fashion, voice and aural perception - although originally sensual - are supposed to provide the highway of abstraction, leading to the permanence and fixity of intellectual ideas above the instability and confusion of the sensual, concrete world. Visual experience and optic signs - forever incapable of rising to the abstract level may even 'contaminate' concepts or ideas, the thinking mind, and the subject with their sensual concreteness, thus making the latter fluid and unstable. If hearing and speech are the ground of continuous and unfailing memory, then sight, writing, and gestures are the allies of forgetfulness (Arnold, 1984; Markowicz, 1972). Again, we can note the considerable influence of logo/phonocentrism (Derrida, 1967) in the history of modern deaf pedagogy.

It is no wonder that from these premises Heinicke came to oppose vehemently the use of sign language in deaf education. The only way for deaf people to gain the ability to think abstractly and conceptually would be, as with Amman, through becoming cured from their sordid state. Thus, the primary goal of deaf education is to teach deaf children to speak and to speech-read from the lips. Heinicke's methods included the use of a model leather tongue to illustrate the correct position of the tongue in the generation of speech sounds (Arnold, 1984).

Heinicke admits that even if deaf persons learn to emit words and to speechread, they do not actually hear the sounds of words. Still, he believed that even this obstacle could be overcome. His solution was somewhat strange. Heinicke contends that the sense of taste could function as something like the substitute for the sense for hearing, and that through this curious detour of taste, the adequate aural experiences of words could still be evoked in the mind of the deaf. As the result, the basis for the evolution of rational, conceptual thinking could finally be constructed (Markowicz, 1972; Lane, 1984, pp. 102-103). Regardless of the obscure nature of his ideas, Heinicke's oralist pedagogy became popular and institutionalized in deaf education in Germany during the late eighteenth and early nineteenth centuries.

Oralism elaborated by Amman and Heinicke was not the only significant strand of deaf pedagogy in eighteenth-century Europe. In France, most notably, it was Abbé Charles Michel de l'Épée (1712-1789) who developed a very different kind of pedagogical thinking and methods for educating deaf children. De l'Épée claimed, first, that gestures are the real natural as well as universal language of humanity. Secondly, he thought that the language of gestures could be 'refined' through methodization, yet without losing its natural origins. In this manner, a silent language of manual gestures could be built, one that was capable of representing even abstract ideas in terms of physical movements. Due to its natural and universal basis, this manual language would be even superior to 
speech. De l'Épée's idea was to divide complex and abstract concepts into elementary, concrete parts, which might be expressed through gestures. The first school for deaf, using de l'Épée's methods, was established in Paris in 1760 , but his insights began to gain support more broadly in Europe (Knowlson, 1965; Seigel, 1969).

As we have found, de l'Épée's pedagogy and method, also known as manualism, are almost the complete opposite of oralism. Indeed, he debated on the issues of deaf pedagogy with Heinicke. Oralism and manualism, the German and French schools, respectively, were the two major, competing veins of deaf education in Europe during the eighteenth and nineteenth centuries. Gradually, their rivalry also reached Scandinavia and Finland.

\section{The arrival and victory of oralism in Finland}

By the mid-nineteenth century, the use of sign language had become fairly common in the education of deaf children in Scandinavian countries. However, it was in this period that a process of profound transformation began to take place. From the mid-nineteenth century on, the oralist discourse and methods, discussed above, began to gain a more secure foothold in Norway and Sweden. This was supported by teachers' increasing fieldtrips to Germany, where Heinickean methods were acquired. The development in Finland followed a similar course. The 1860 s were a period during which the entire Finnish system of elementary education underwent a profound transformation. In 1869, elementary schools were detached from the Lutheran Church. Uno Cygnaeus (1810-1888) - a clergyman, educator, and the chief inspector of the Finnish school system - is often named as the 'father' of the Finnish public-school institution. In his study trips around Europe, Cygnaeus became acquainted also with schools specialized in the education of deaf children. He was particularly impressed by the Weissenfels School in Germany, which was a pioneer in the application of oral notions and methods. Cygnaeus had a significant role in the initial rooting of oralism in Finnish schools, and in launching the parallel process of the marginalization of sign language during the second half of the nineteenth century (Salmi \& Laakso, 2005).

Besides Cygnaeus, the Finnish teacher G.K. Hendell (1843-1878) was one of the key figures in the importation and consolidation of German oralist pedagogy in Finland. Hendell made a visit to Swedish and Norwegian deaf schools, and also worked at Manilla school in Stockholm, where the oral method of teaching was already firmly established. There, he adopted the tenets of German pedagogy and brought them to Finland. Hendell was given the opportunity to put them into practice when he became the director of the school for deaf-mutes in Kuopio in 1874 (Salmi \& Laakso, 2005, p. 151).

In the course of the late 1800s, the hegemonization of oralist pedagogy progressed in Finnish deaf education. To encapsulate, this was a period in which the aims and methods of special education were taken into more strict state control. The objective of making the deaf speak and the oral method became ossified as primary, far more crucial than any other subject matter taught and their contents (Salmi \& Laakso, 2005, pp. 155-159, 170). Meanwhile, various new schools for deaf children were opened in different parts of Finland. An official committee memo from 1907 asserted that through compulsory education and schooling, organized to meet their special needs, the deaf population could be integrated as members of Finnish society, able to make their own living by normal, productive work (Salmi \& Laakso, 2005, pp. 159, 162). Finally, in 1921 (after the civil war) Finnish Parliament passed the law on 
generalized compulsory education, making no exception for deaf children (Salmi \& Laakso, 2005, p. 162).

The institutionalization of oralist pedagogy - together with the marginalization of sign language and manualism - continued in Finland during the twentieth century. Many teachers themselves acknowledged that sign language was felt by deaf pupils themselves to be their own, 'natural language' that they used with ease. However, this 'naturalism' and spontaneous facility of silent, visual signs and the parallel difficulty and anguish in oral teaching were often regarded as yet another piece of evidence on the primitive, animalistic and deficient nature of sign language, and on the superiority of vocal speech. The Finnish discourse of special education leaned particularly on Heinicke, and considered sign language, at best, only suitable for the expressions of the 'will of the deaf', but not a medium of conceptual thinking and abstract reasoning. It was condemned as inherently and irreparably confused, ambiguous, and insufficiently articulate. The effort, pain, and even the use of physical violence in oralist education were regarded as both justified and necessary in the task of turning the deaf into speaking beings, which also meant releasing them from their animalistic, concrete, sensual, and affective mode of life. In line with the ideas of Amman and Heinicke (see above), the task of deaf education was to make the deaf speak and understand speech, and as a result, to transform them into reasoning, concept-using, and self-governing human beings. In the early decades of the twentieth century, one of the notable and very articulate advocates of these views was the teacher Veikko Lehvä (Salmi \& Laakso, 2005, pp. 172-175).

\section{Finnish oralism after World War II}

These oralist notions kept their dominant status in Finnish deaf education through the first few decades of the twentieth century, in spite of opposition from both deaf people and some teachers (Salmi \& Laakso, 2005, pp. 172-177). After World War II, Germany lost its position in Finland as the major source of pedagogical ideas and methods. Yet this did not mean that the basic tenets of oralism, as scrutinized above, lost their impact. In the 1950s, American pedagogical ideas began to play a more central role in Finnish special education. Still, the elementary oralist notions remained central. For instance, Finnish educators became inspired by the John Tracy clinics, which proposed that it is the task of each mother to start teaching her deaf child to speak as early as possible, already before school (Salmi \& Laakso, 2005, pp. 181-183).

There is one seminal Finnish contribution following World War II to the psychological study of deafness that needs to be discussed from the perspective of oralism. Jyrki Juurmaa (1929-2010) was a Finnish psychologist who conducted research on 'sensory deficiencies', both blindness and deafness, and their effects on the development of mental 'ability structures'. Juurmaa was in his time a somewhat influential figure in Finnish academic culture. Moreover, he forged relations of close collaboration with American researchers and has attracted international attention.

Juurmaa implemented various tests on the mental performances of deaf and hearing persons and then compared the results. Interestingly, his studies do not refute the core notions of oralism, already familiar to us from the seventeenthand eighteenth-century discourse of Amman and Heinicke. Rather, these notions are translated into the language of psychology after World War II. On the basis of the tests, Juurmaa's study proposes that for the minds of deaf persons, it is the concrete, perceived details that are predominant. In those 
mental tasks in which concrete empirical material is presented and operations of reasoning remain attached to immediate perception, the performance of the deaf matches those of the hearing (Juurmaa, 1963).

Contrariwise, the deaf are considerably weaker than the hearing in those tasks that require abstract reasoning, non-concrete ideation, and application of general principles to concrete instances (Juurmaa, 1963). 'On verbal ability, numerical ability and reasoning the hearing were definitely superior to the deaf' (Juurmaa, 1967, p. 118). Juurmaa (1967) proposes that blind are superior to the 'normal' precisely in the abstract numerical abilities or arithmetic. Furthermore, Juurmaa submits that when it comes to the linguistic abilities of acquiring and mastering verbal symbols, the deaf cannot surpass the 'ostensive' level, that is, the stage where concepts are understood and acquired with the help of empirical demonstration. Therefore, abstract concepts that are difficult or impossible to teach through ostentation can only stay incomprehensible and alien to them (Juurmaa, 1963).

Indeed, as a result of the psychological tests and comparisons, what reemerges is the binary setting that is already quite familiar to us from the earlier oralist discourses. Once again, the ear and sense of hearing are posed as the origin and condition of the higher conceptual-abstract activities of the mind, while the lack of hearing and the silent visuality of the deaf mind are defined as a decisive deficiency, a pathology/abnormality that inflicts the whole mind and subjectivity. The lack of audition deprives the subject of the capacity of conceptual, abstract and theoretical thinking, and as a result, of the mastery of the world and her/himself. The deaf remain passively captivated by the flux of immediate sensations and affects, akin to animals:

Correspondingly, the crucial and most interesting problem in the study of the deaf is: How is it possible to learn language and to acquire a body of concepts without the sense of hearing? (...) the crux of the problem (...) relates $(. .$.$) in the case of the deaf to theoretical mastery of the world.$ (Juurmaa, 1963, Introduction, emphasis added)

As it turns out, the seventeenth- and eighteenth-century oralist notions of deafness proved to be insidious in twentieth-century psychology, including in Finland. This being the case, it is not surprising that the oralist methods persisted in the education of deaf children in the 1970s in Finland, despite the rise of the deaf pride and deaf awareness movements, which began to demand guaranteed education and teaching in sign language (Salmi \& Laakso, 2005). It was not until 1995 that the Finnish Parliament, as a part of the Finnish reform of basic rights, legally recognized the status of sign language. Still today, much remains to be done when it comes to the practical realization of the equal status of sign language in education, especially in Finnish Universities (Salmi \& Laakso, 2005).

\section{Foucault and the silence of discipline}

The applicability of Foucault's seminal analyses of modern disciplinary, surveying, and normalizing power (Foucault 1979; 2003; 2004) of the 1970s is fairly obvious when it comes to the history of deaf education in general, including the case of Finland. The oralist pedagogic doctrine and methods, as well as their institutionalization in deaf schools, can be seen as an exemplar of a more pervasive transformation in the eighteenth century. In this historical shift, the school becomes a disciplinary institution (along with the mental asylum, prison, and so on) that seeks to produce normal, docile, productive, and beneficial 
individual subjects that survey and control themselves (Bauman, 2004; Branson \& Miller, 2002; Lane, 2002).

If we examine Foucault's insights more closely, things become much more complex. Foucault himself does not consecrate any explicit treatment to the medicalization and normalization of deafness, unlike for instance, of homosexuality or children's masturbation. Still, I suggest there is an essential link between Foucault's genealogy of modern discipline and normalization and the history of deaf education, one that has hardly been noted before. This link is unveiled if we scrutinize the roles played by different modalities of sensual perception and experience, by the eye and the ear, by optic and aural experience, respectively, in Foucault's integrally interrelated notions of surveillance, discipline, and normalization (Foucault 1979; 2003; 2004). In other words, we need to explore what the role of visual and aural perception and experience is in the operation of disciplinary and normalizing power, but also in their product, which is the normal subject. This means asking which account of normalizing and normal perception and sensuality is to be discovered in Foucault's take on discipline and normalization. Concomitantly, it means inquiring, what the reverse of this is, that is, the view of abnormal or pathological sensuality and perception. The next step is to query how this Foucauldian account of disciplinary and normal sensuality relates to and compares with that major construction of the normal perceiving subject, which we have already exposed in the history of modern oralist pedagogy and deaf education, and in the Finnish case in particular.

As discussed earlier, at the very nucleus of oralist discourse - ranging from its seventeenth- and eighteenth-century origins in Amman and Heinicke up until the work of Juurmaa in the 1960s in Finland - there is the normative idea of a determinate kind of sensual and perceiving subject: the speaking and hearing subject, the subject of auditory experience (or its simulation), whose normality, whose rationality, whose self-government, and whose productivity are underpinned by speech and aural experience. We also saw that in the oralist discourse, visuality and optic experience without voice, the silent language of manual gestures, were attached to abnormality and pathology, to irrationality and lack of self-government. In oralist special education, normalization was inseparably associated with curing deafness, with making the deaf speak and hear.

Undoubtedly, the most widely known idea in Foucault's work of the 1970s (and possibly in his thinking taken as a whole) is the Panopticon (Foucault, 1979). For Foucault, it is the general, modern scheme of surveillance, disciplinary power, and normalization. Foucault developed the analysis already in his lectures during the early 1970s at the Collège de France, but it became generally known through Discipline and Punish (originally published in 1975). As is generally known, generalized and continuous surveillance - or the illusion of being continuously surveyed - is the modus operandi of the Panopticon. It is pivotal to remember that the panoptic scheme of surveillance, its modus operandi, its logic of functioning, and its effects are not just one particular technique of power among others. Panoptic surveillance is operative, in one way or another, in all modern disciplinary and normalizing power, in all of its various institutionalized forms. To put it briefly: There is no modern discipline or normalization that would operate without panoptic surveillance (Foucault, 2001).

Consequently, what Foucault has to say of panoptic surveillance has implications for his entire account of discipline and normalization. What he states on the role of senses and sensual perception in panoptic surveillance has 
implications to his entire notion of modern discipline and normalization. From this perspective, it is of utmost importance for us to note how strongly Foucault emphasizes the key role of optic-visual perception in the operation of panoptic surveillance. Foucault not only highlights the central function of invisible visibility, that is, the experience of being seen all the time by the gaze that stays hidden. He presents the much more forceful claim that it is a mode of power which is purely and exclusively based on optics and visibility:

The Panopticon means two things: it means that all is seen all the time, but it means also that all the power that is exercised is never anything but an effect of optics (...) This power is rather of the order of the sun, of the perpetual light, it is the immaterial illumination, which is shed indifferently on all the people on whom it is exercised. (Foucault, 2003, p. 79, emphasis added)

The Panopticon works solely through optics and visibility, in other words, through illumination and providing visibility. We can infer that the gaze and the seeing are also what make things visible and throw light so that things show themselves. By these purely visual-optic, immaterial means the panoptic dispositive produces its most profound effect, which is not the detection of transgressive behaviour, but the production and maintenance of individuality individual, self-governing, and docile, normal subjectivity. Whether we are dealing with modern prisons, mental institutions, schools or factories, the same optic-visual techniques are at play (Foucault, 1979; 1997; 2001; 2003).

One can read Foucault's account of the all-intrusive panopticism of modern society as a critical response to Guy Debord's diagnosis of the 1960s, according to which modern society is essentially a society of the spectacle. Nonetheless, similar to Debord's (1999) 'spectacle', the Panopticon is also an apparatus of power that is essentially visual-optic in its performance. In both cases, it is sight, gaze, and seeing that spawn the effects of objectification, individualization, division, separation, and isolation (Foucault, 1979; 2001).

In the working of the panoptic apparatus, as Foucault understands it - and consequently in all the numerous institutions of discipline and normalization, which cannot operate without panoptic surveillance - there is neither use nor need for other sensory modalities except vision. Nevertheless, in Jeremy Bentham's original, late-eighteenth-century depiction of the panoptic scheme, we discover that this is not the case. There, the ear and aural perception are indeed given a function in the deployment of surveillance:

Complaints from the sick might be received the instant the cause of the complaint, real or imaginary, occurred (...) Here the use of the tin speaking-tubes would be seen again, in the means they would afford to the patient, though he were equal to no more than a whisper, of conveying to the lodge the most immediate notice of his wants (...). (Bentham, 1995, Letter XX)

Foucault recognizes that the tin tubes, hearing, and aural experience figure in Bentham's scheme, but is nevertheless unwilling to ponder their significance any further. When Michelle Perrot draws attention to this issue in a discussion, Foucault does not take this initiative (Foucault, 2001). ${ }^{2}$ In Discipline and Punish, all we find is a footnote, which briefly points out that Bentham later expressed some hesitations about the usefulness of the tin tubes (Foucault, 1979, p. 317,

2 To compare, we meet reflections on hearing, listening, and surveillance along these lines in Roland Barthes (1982, pp. 217-220). 
no. 3). In my opinion, all this shows Foucault's reluctance to question his own belief in the purely and exclusively visual-optic modus operandi of modern surveillance, discipline, and normalization, pertaining to all their various institutional arrangements and the concomitant absence of the ear and aural experience.

For Foucault, modern discipline, surveillance and normalization operate in and through silent visuality. It is through silent visuality, in the absence of hearing and aural experience, that these modern forms of power produce their most profound effect: the normal, self-observing, and self-governing individual subject. When surveillance and discipline become internalized into the selfrelation of the subject, the silent, optic-visual experience continues to be the key vehicle of power. In Foucault's genealogy of discipline and normalization, the normal subject is the seeing subject. It is not the hearing or vocal subject. In even more radical terms, the normalized and docile subject of Foucauldian modernity is akin to the image of the deaf subject, constituted in and through silent visuality, in the absence and deprivation of other sensual modalities, such as aurality. In Foucauldian discipline and normalization, there is hardly any room for something like aural-oral normalization and aural-oral normality, aural-oral subject of self-government, and aural-oral docility. However, as demonstrated above, it is precisely the fabrication of aural-oral normal subjectivity which is at the core of the modern oralist discourse and practices of deaf education, in Finland as elsewhere.

Inversely, the ear, voice, sound and aural experience are very much present when it comes to Foucault's depiction of the adversaries of the modern discipline and normalization. In 1970s Foucault, masses, crowds, and multitudes all refer to resistance that confronts disciplinary and normalizing power. In various instances, when Foucault characterizes these masses, crowds, and multitudes, he states that they are emitting sounds. The masses are howling, or they generate chatter and chanson. Foucault associates these sounds with some of the central qualities of the masses: centrifugal mobility, movement in which bodies and forces spread, generating multiple horizontal contacts with one another. The horizontal conjunctions forge a merging, mingling or confusion between individualities (Foucault, 1979).

It appears that sound and aural perception belong to these 'massy', dynamic, and horizontal relations. What transpires in such relations - including noise, chatter, and chanson - is transition or contagion. This can occur between states of mind, between affects or between tasks and their performances (as collective distractions). Through sounds and hearing, the subjects share with each other what ought - according to the logic of disciplinary individualization - to remain separate. Crowds, masses, and multitudes collide with disciplinary power, which strives to individualize, and through individualization, to take care of the usefulness and productivity of bodies and forces.

It seems that from the perspective of discipline and normalization, just like other horizontal relations and dynamics of bodies, sound and aural experience find themselves under suspicion. In Foucault, we end up with a setting, in which silent, visual-optic normalization clashes with the aural, noisy dissolution of the individual subject. In the strand of oralist pedagogy that we have followed, from Amman and Heinicke to 1960s Finland, it is rather the opposite: It is the silent visuality and manualism of the deaf culture that are defined as the dangerous origin of de-subjectivation, the loss of self-government, and the affective 'animalization' of human beings. 


\section{Conclusions}

In Foucault's genealogy of modern discipline and normalization, what is absent is any insight on the auditory-phonetic-oral determination and spawning of the normal subject and normalization in modern institutions. Foucault is somewhat reluctant even to ponder the potential role of such a form of auditory power. Yet, as exposed in this article, it is precisely the ear, hearing, and aural experience, through which the normal, rational, and self-governing individual subject was fabricated in modern oralist pedagogy. This whole history of pedagogic as well as psychiatric-medical power, as it took place in Finland among other countries, seems to contradict Foucault's notion of the regime of perception and sensual experience, so central in his view of modern discipline, surveillance, and normalization. In Foucault's account, the latter revolves strictly around the eye, gaze, and visibility, deployed in silence, in the absence of voice and aural experience. Furthermore, if we follow Foucault, there is a conflictual relationship between disciplinary-normalizing power, on one hand, and sound and aural experience, on the other. This conflict ensues from the very logic of the disciplinary dispositif itself. Sound and aural experience belong together with the enemies of discipline and normalization, that is, with crowds and masses and the affective loss of conceptual thinking and self-government.

To recapitulate, what we have witnessed in the history of deaf education, stressing the Finnish case - the auditory-oral-vocal construction of the normal, rational, concept-using, and self-governing subject, and the pathologization/abnormalization of silent visuality - appears as something like an anomaly in relation to Foucault's genealogy. In this way, we are invited to question the deep-seated binary setting of the eye and the ear, which relates the first with calmness, order, harmony, and stability of soul and community alike, and the second with madness, rapture, and subversion. In a way, we may conclude that this binary setting inverses the one that was active in the oralist discourse of deaf education, in which the ear is the source of stability and reason, whereas the eye is the origin of animalistic instability. The pertinence of this problematic is certainly not limited to reading Foucault. Western critical theory and critical thinking need self-critical reflection on their own sensoryperceptual presuppositions. Otherwise, they risk becoming uncritical to the variety of powers operating through various different sensory modalities. This is something that social and political theory could learn from studying the history of the deaf.

\section{References}

Allan, J., Brown, S. \& Riddell, S (1998). Permission to speak? theorising special education inside the classroom. In C. Clark et al. (Eds.) Theorising special education (pp. 21-32). Abingdon and New York: Routledge.

Allan, J. (2007). Rethinking inclusive education: the philosophers of difference in practice. Dordrecht: Springer.

Amman, J.C. (1873). A dissertation on speech. London: Sampson Low, Marston, Low, and Searle.

Amman, J.C. (1694). The talking deaf man. London: Tho. Hawkins.

Arnold, P. (1984). The education of the deaf child: for integration or autonomy? American annals of the deaf, 129(1), 29-37.

NJSR - Nordic Journal of Social Research 
Barthes, R. (1982). L'obvie et l'obtus: essais critiques III. Manchecourt: Éditions du Seuil.

Bauman H.-D. (2004). Audism: understanding the metaphysics of oppression. Journal of deaf studies and deaf education, 9(2), 239-246.

Bauman, H.-D. (2008). Listening to phonocentrism with deaf eyes: Derrida's mute philosophy of (sign) language. Essays in philosophy, 9(1), article 2.

Bentham, J. (1995). The Panopticon writings. London: Verso.

Branson, J. \& Miller, D. (2002). Damned for their difference: the cultural construction of deaf people as disabled. Washington DC: Gallaudet University Press.

Debord, G. (1999). The society of the spectacle. New York: Zone Books.

Derrida, J. (1967). Of grammatology. Baltimore: The Johns Hopkins Press.

Foucault, M. (1979). Discipline and punish: the birth of the prison. New York: Vintage Books.

Foucault, M. (1997). 'Il faut défendre la société'. Cours au Collège de France ['The society must be defended'. Course at the Collège de France]. 1976. Paris: Gallimard/Seuil.

Foucault, M. (2001). L'oeil du pouvoir [The eye of power]. In D. Defert \& F. Ewald (Eds.) Michel Foucault: Dits et écrits II. 1976-1988 (pp.190-207). Paris: Gallimard.

Foucault, M. (2003). Le pouvoir psychiatrique. Cours au Collège de France [Psychiatric power. Course at Collège de France]. 1973-1974. Paris: Gallimard/Seuil.

Foucault, M. (2004). Securité, territoire, population. Cours au Collège de France [Security, Territory, Population. Course at Collège de France]. 1977-1978. Paris: Gallimard/Seuil.

Juurmaa, J. (1963). On the ability structure of the deaf. Jyväskylä: OY Keskisuomalainen kirjapaino.

Juurmaa, J. (1967). The ability structure of the blind and the deaf: final report. In Clark, L.L. (Ed.) Research Bulletin No (pp. 109-123). New York: American Foundation for the Blind.

Knowlson, J.R. (1965). The idea of gesture as a universal language in the $17^{\text {th }}$ and $18^{\text {th }}$ Centuries. Journal of the history of ideas, 26(4), 495-508.

Lane, H.L. (1984). When the mind hears: a history of the deaf. New York: Random House.

Lane, H.L. (2002). Do deaf people have a disability? Sign language studies, 2(4), 356379.

Markowicz, H. (1972). Some sociolinguistic considerations of American sign language. Sign language studies, 1, 15-41.

Salmi, E. \& Laakso, M. (2005). Maahan lämpimään: Suomen viittomakielisten historia [Into the warm ground: the history of Finnish people using sign language]. Helsinki: Kuurojen liitto ry [Finnish Society of the Deaf].

Seigel, J.P. (1969). The enlightenment and the evolution of a language of signs in France and England. Journal of the history of ideas, 30(1), 96-115.

Tremain, S. (Ed.). (2005). Foucault and the government of disability. Michigan: The University of Michigan Press. 